\title{
Prevalence of gastrointestinal parasites in equines of Mustang District, Nepal
}

\author{
RAVI PRASAD DEVKOTA ${ }^{1}$, JANAK RAJ SUBEDI ${ }^{1, \boldsymbol{\gamma}}$, KOPILA WAGLEY ${ }^{2}$ \\ ${ }^{1}$ Central Department of Zoology, Tribhuvan University. Kirtipur, Kathmandu, Nepal. "email: janzoology@ gmail.com \\ ${ }^{2}$ Central Department of Environmental Science, Tribhuvan University. Kirtipur, Kathmandu, Nepal
}

Manuscript received: 12 July 2021. Revision accepted: 27 August 2021.

\begin{abstract}
Devkota RP, Subedi JR, Wagley K. 2021. Prevalence of gastrointestinal parasites in equines of Mustang District, Nepal. Biodiversitas 22: 3958-3963. The study was conducted from March 2018 to November 2018 in four villages of Mustang district to find out the prevalence of gastrointestinal parasites in equines (horses and mules). Fecal samples collected from 175 randomly selected equines (105 from horses and 70 from mules) were preserved in $2.5 \%$ potassium dichromate and microscopically examined using concentration techniques to detect ova, larvae, and oocysts of parasites. The overall prevalence of gastrointestinal parasites was found to be $84.57 \%$ with an incidence rate of $81.90 \%$ and $88.57 \%$ in horses and mules respectively. The prevalence of gastrointestinal parasites between horses and mules did not vary significantly $(p>0.05)$. Also no significant association $(p>0.05)$ between the prevalence rate of parasites and study areas was observed. Among identified parasites in horses, Strongyles showed the highest prevalence (68.57\%) followed by Strongyloides spp. (23.80\%), and Parascaris equorum (14.28\%) and in mules Strongyles showed the highest prevalence (80.0\%) followed by Parascaris equorum (35.71\%), Strongyloides spp. (28.57\%), and Dictyocaulus spp. (5.71\%). Prevalence of gastrointestinal parasites showed no significant variation $(\mathrm{p}>0.05)$ with respect to age and feeding status. However, the prevalence rate significantly varied $(\mathrm{p}<0.05)$ with respect to parameters like infection status (single and mixed), housing condition and health status. The present study revealed a higher prevalence rate of gastrointestinal parasites due to poor husbandry practices and lack of adequate veterinary services. Therefore, improvement in housing and feeding system, awareness regarding effective regular deworming, and establishment of veterinary hospitals in the study areas were recommended.
\end{abstract}

Keywords: Gastrointestinal parasites, horses, mules, Mustang District, prevalence

\section{INTRODUCTION}

Equine power is essential for both rural and urban transportation networks since it is inexpensive and provides the greatest option in situations where the road network is inadequate in mountainous regions and towns with narrow streets. Equines play a crucial role in urban and rural areas, providing agricultural energy and transport. In many cases, the sole means of income-generating for their resourcelimited owners (Getachew et al. 2014). The equine population in the world is about 122.4 million with $35 \%$ being horses, 33\% donkeys, $20 \%$ zebras and camels, and $12 \%$ mules (Ali et al. 2018). Globally $98 \%$ of donkeys, $97 \%$ of mules, and $60 \%$ of horses are concentrated in developing countries (Tedla and Abichu 2018). As per Statistical Information on Nepalese Agriculture, Nepal has a total of 55,808 equine populations with around 2000 equines in Mustang district. There has been a gradual decline in equine population since 1980's due to road construction, reduction in grassland and forest area, and to some extent, availability of air transport. However, mules are still primarily used for domestic good transport in the track of high and mid mountains of Nepal. Most of the mules being used in Nepal are brought from neighboring part of India and only a few of them are native breeds.

Equines harbor a large number of parasites in the Gastrointestinal tract causing varying degrees of damage depending on the age, nutritional and immune status of equines (Asefa et al. 2011). Gastrointestinal helminth infections, particularly nematode and trematode infections, have a significant impact on livestock output by causing death and morbidity and expenses associated with control and treatment (Lashari and Tasawar 2011). Moreover, the infection is associated with loss of digestive function, decreased fertility and poor body condition of animals (Brady and Nichols 2009). Among different groups of the helminths, large strongyles are the most pathogenic gastrointestinal parasites of equines (Sori et al. 2017). A number of studies conducted to detect an association between poverty and animal diseases have identified gastrointestinal parasitism as one of the most important problems for equids in developing countries (Mezgebu et al. 2013).

In Nepal, few studies are available from different parts of the country regarding the prevalence of gastrointestinal parasitism in equines and have reported prevalence ranging from $45 \%$ to $100 \%$ (Karki and Manandhar 2006; Sapkota 2009). Apart from few reports in other parts of Nepal, there was no specific previous information on intestinal parasites of equines in Mustang district, Nepal. Therefore, this study was carried out in four villages of Mustang district to know the current prevalence of gastrointestinal parasites and the association of prevalence with different risk factors. 


\section{MATERIALS AND METHODS}

\section{Study area}

Mustang District is located in Nepal's Gandaki Province in between $28^{\circ} 33^{\prime} 51^{\prime \prime}$ North to $29^{\circ} 19^{\prime} 52^{\prime \prime}$ North latitude and $83^{\circ} 28^{\prime} 54^{\prime \prime}$ east to $84^{\circ} 14^{\prime} 58^{\prime \prime}$ east longitude. The district stands at the Himalayas and expands northward onto the Tibetan plateau. It is a vast and arid valley, distinguished by eroded canyons, vividly colored stratified rock formations, and barren high-altitude deserts with very sparsely distributed households where the residential area comprises only $0.08 \%$ of the total area. The study area receives an average annual rainfall of less than $260 \mathrm{~mm}$. The average minimum monthly air temperature drops down to $-2.7^{\circ} \mathrm{C}$ in winter while the maximum monthly air temperature reaches to $23.1^{\circ} \mathrm{C}$ in summer. The whole district is located within the Annapurna Conservation Area. The study areas selected included Thini, Muktinath, Surkhang and, Lomanthang of Mustang district, and the altitude of the study area varied from $2,500 \mathrm{~m}$ to $3,800 \mathrm{~m}$ above sea level.

\section{Study design and samples collection}

A total of 175 freshly defecated fecal samples were taken between 4 a.m. to 6 a.m. In this study, only one host animal per dwelling was chosen. Four villages in the Mustang district were chosen to guarantee consistent sampling in order to reflect the entire study area. Each village provided a different number of samples. Of the total samples collected $(\mathrm{n}=175)$ horses and mules comprised 105 and 70 samples respectively. Collected fecal samples were kept inside the clean plastic vial and preserved in $2.5 \%$ potassium dichromate. Each sample was labeled with its corresponding date, location, species, housing and feeding condition, age and, health status of the host animal. Age of the animals was determined using dentition and information provided by the owner (Mezgebu et al. 2013). Equines below three years were classified as young, those in the range of three to ten years were classified as adults and above ten years were classified as old (Debere et al. 2018). The housing that provided enough resting space, thermal comfort and ease of movement for animals were considered as good housing (Ivet 2020). Whereas, housing where equines couldn't withstand cold weather and heavy rains with lack of proper and sturdy fencing, unclean and wet area for feeding, and where equines could not stand up freely or lie down comfortably were considered poor housing. Similarly, the health status of equines under the study was divided into three categories i.e. healthy, weak and, emaciated on the basis of their physical appearance/body condition (Ali et al. 2018). The imperturbable samples were brought to the laboratory of the Central Department of Zoology, Kirtipur, Kathmandu and were processed after 72 hours as immediate processing was not possible.

\section{Coprological examination}

The fecal samples were subjected to coprological examination by concentration techniques (flotation and sedimentation). Approximately $3 \mathrm{~g}$ of fecal sample was taken in a beaker and $50 \mathrm{ml}$ of water was poured and mixed thoroughly. The fecal suspension was run through a tea strainer into another beaker. Then the fecal suspension was poured into a centrifuge tube of $15 \mathrm{ml}$ and centrifuged at 2,000 rpm for 5 minutes. The tube's water was replaced with saturated sodium chloride solution and was again centrifuged. More saturated sodium chloride solution was gently filled leaving a convex meniscus surface at the top of the tube and a coverslip was carefully placed on the top of the tube. Then the tube was let to stand for $20 \mathrm{~min}$. The coverslip was removed and placed gently on a clean glass slide and examined under the microscope. After the examination of the flotation portion, the sediment content was poured into the watch glass and stirred gently to mix it. One drop from the mixture was taken on slide and stained with iodine to examine under the microscope. The eggs and larvae present in the positive fecal samples were identified using standard key based on their morphological traits as described by Soulsby (1982). The L3 larvae of Dictyocaulus spp. were recovered from mules' fecal samples by Baermanns technique and were identified using a stereomicroscope.

\section{Data management and analysis}

The data collected from the study were coded and entered in a Microsoft Excel spreadsheet and, the statistical analysis was performed using SPSS, version 25 software packages. The chi-square test was used to assess the difference in the frequency of gastrointestinal parasites among different variables like equine species, study area, infection status, age, feeding condition, housing condition and health status. The percentage was used to calculate the prevalence rate of gastrointestinal parasites. In all cases, 95\% confidence interval (CI) and $\mathrm{p}<0.05$ were considered for a statistically significant difference.

\section{RESULTS AND DISCUSSION}

An overall $84.57 \%$ (148/175) prevalence of gastrointestinal parasites was observed with $81.90 \%$ (86/105) and $88.57 \%$ (62/70) prevalence in horses and mules respectively, the difference being statically nonsignificant ( $p \geq 0.05$ ) between horses and mules (Table 1). Among identified parasites in horses, the Strongyle worm eggs showed the highest prevalence $(68.57 \%)$ followed by Strongyloides spp. (23.80\%) and Parascaris equorum $(14.28 \%)$. Similarly, in mules the eggs of Strongyles showed the highest prevalence (80\%) followed by Parascaris equorum (35.71\%), Strongyloides spp. (28.57\%) and larvae of Dictyocaulus spp. (5.71\%) (Table 2).

Among four study areas, the highest prevalence in horses was revealed from Muktinath followed by LoManthang, Thini and Surkhang with the prevalence of $90.47 \%, 84.21 \%, 66.66 \%$ and $60.0 \%$ respectively. Similarly, the highest prevalence in mules was revealed from Muktinath followed by Lomanthang, Thini and Surkhang with the prevalence of $100 \%, 93.33 \%, 87.5 \%$ and $81.81 \%$ respectively. The study showed no statistically significant difference ( $>0.05)$ between the study area and 
the prevalence of gastrointestinal parasites in both horses and mules (Table 3).

Both horses and mules were found to be infected with single and mixed gastrointestinal parasites infection. In the current study, single infection was observed in $60.95 \%$ of horses and $38.57 \%$ of mules (Table 4) while the mixed infection was found in $20.95 \%$ of horses and $50 \%$ of mules (Table 5) and a significant association $(\mathrm{p}<0.05)$ was observed between the infection status (single and mixed) and prevalence of gastrointestinal parasites among horses and mules (Tables 4 and 5). The data were further analyzed with respect to different risk factors such as age, feeding status, housing condition and, health status of equines. The prevalence in young equines was $93.33 \%$ while the prevalence in adult and old equines was $83.05 \%$ and $85.71 \%$ respectively. A higher prevalence $(88.57 \%)$ was observed among equines that graze on pastures while poor housing conditions contributed to the prevalence of
$89.32 \%$. Based on the health status of equines the prevalence of gastrointestinal parasites was $100 \%$ in emaciated equines, $91.30 \%$ in weak and $79.46 \%$ in strong equines Prevalence of gastrointestinal parasites showed no significant difference $(p>0.05)$ with respect to age and feeding status. However, the prevalence rate was significantly associated $(\mathrm{p}<0.05)$ with housing conditions and health status (Table 6).

Table 1. Overall Prevalence of gastrointestinal parasites in equines

\begin{tabular}{cccccc}
\hline Equines & $\begin{array}{c}\text { No. of } \\
\text { animal } \\
\text { examined }\end{array}$ & $\begin{array}{c}\text { No. of } \\
\text { animal } \\
\text { positive }\end{array}$ & $\begin{array}{c}\text { Prevalence } \\
(\%)\end{array}$ & $\chi^{2}$ & $\begin{array}{c}\text { p- } \\
\text { value }\end{array}$ \\
\hline Horse & 105 & 86 & 81.90 & 13.385 & $0.342^{\#}$ \\
Mule & 70 & 62 & 88.57 & & \\
Total & 175 & 148 & 84.57 & & \\
\hline
\end{tabular}

Note: \#: Statically non-significant

Table 2. Types of gastrointestinal parasites observed in horses and mules on coprological examination

\begin{tabular}{lcccccc}
\hline \multirow{2}{*}{ Egg/larvae of parasite } & \multicolumn{3}{c}{ Horse } & \multicolumn{2}{c}{ Mule } \\
\cline { 2 - 7 } & Total examined & Positive & Prevalence (\%) & Total examined & Positive & Prevalence (\%) \\
\hline Strongyles & 105 & 72 & 68.57 & 70 & 56 & 80 \\
Strongyloides spp. & 105 & 25 & 23.80 & 70 & 20 & 28.57 \\
Parascaris equorum & 105 & 15 & 14.28 & 70 & 25 & 35.71 \\
Dictyocaulus spp. & 105 & 0 & 0 & 70 & 4 & 5.71 \\
Total & 105 & 86 & 81.90 & 70 & 62 & 88.57 \\
\hline
\end{tabular}

Table 3. Area wise prevalence of gastrointestinal parasites in horses and mules

\begin{tabular}{|c|c|c|c|c|c|c|}
\hline \multirow{2}{*}{ Study Location } & \multicolumn{3}{|c|}{ Horse } & \multicolumn{3}{|c|}{ Mule } \\
\hline & Total examined & Positive n(\%) & $\chi^{2}$ (p-value) & Total examined & Positive n(\%) & $\chi^{2}$ (p-value) \\
\hline Thini & 15 & $10(66.66)$ & 7.80 & 24 & $21(87.5)$ & 2.51 \\
\hline Muktinath & 42 & $38(90.47)$ & $(0.052)^{\#}$ & 9 & $9(100)$ & $(0.472)^{\#}$ \\
\hline Surkhang & 10 & $6(60)$ & & 22 & $18(81.81)$ & \\
\hline Lo-Manthang & 38 & $32(84.21)$ & & 15 & $14(93.33)$ & \\
\hline Total & 105 & $86(81.90)$ & & 70 & $62(88.57)$ & \\
\hline
\end{tabular}

Note: : : Statically non significant

Table 4. Prevalence of single infection of gastrointestinal parasites in horses and mules

\begin{tabular}{lcccc}
\hline \multirow{2}{*}{ Egg/larvae of parasite } & \multicolumn{2}{c}{ Horse } & & Mule \\
\cline { 2 - 5 } & No. of positive & Prevalence (\%) & No. of positive & Prevalence (\%) \\
\hline Strongyles & 50 & 47.61 & 22 & 31.42 \\
Strongyloides spp. & 9 & 8.57 & 2 & 2.85 \\
Parascaris equorum & 5 & 4.76 & 3 & 4.28 \\
Dictyocaulus spp. & 0 & 0 & 0 & 0 \\
Total & 64 & 60.95 & 27 & 38.57 \\
\hline
\end{tabular}

Table 5. Prevalence of mixed infection of gastrointestinal parasites in horses and mules

\begin{tabular}{lcccc}
\hline \multirow{2}{*}{ Egg/larvae of parasite } & \multicolumn{2}{c}{ Horse } & \multicolumn{2}{c}{ Mule } \\
\cline { 2 - 5 } & No. of positive & Prevalence (\%) & No. of positive & Prevalence (\%) \\
\hline Strongyles and Strongyloides spp. & 13 & 12.38 & 9 & 12.85 \\
Strongyles and Parascaris equorum & 7 & 6.66 & 13 & 18.57 \\
Strongyloides spp. and Parascaris equorum & 0 & 0 & 1 & 1.42 \\
Strongyles and Dictyocaulus spp. & 0 & 0 & 4 & 5.71 \\
Strongyles, Strongyloides spp. and Parascaris equorum & 3 & 2.85 & 3 & 11.42 \\
Total & 22 & 20.95 & 35 & 50 \\
\hline
\end{tabular}


Table 6. The prevalence of gastrointestinal parasites with respective categories of the risk factors in the study area

\begin{tabular}{|c|c|c|c|c|c|}
\hline Risk factor & $\begin{array}{c}\text { No. of } \\
\text { animal } \\
\text { examined }\end{array}$ & $\begin{array}{c}\text { No. of } \\
\text { animal } \\
\text { positive }\end{array}$ & $\begin{array}{l}\text { Prevalence } \\
\quad(\%)\end{array}$ & $\chi^{2}$ & p-value \\
\hline \multicolumn{6}{|l|}{ Age } \\
\hline Young & 15 & 14 & 93.33 & 1.13 & $0.567^{\#}$ \\
\hline Adult & 118 & 98 & 83.05 & & \\
\hline Old & 42 & 36 & 85.71 & & \\
\hline \multicolumn{6}{|l|}{ Feeding } \\
\hline Pasture & 70 & 62 & 88.57 & 1.55 & $0.458^{\#}$ \\
\hline Mixed & 96 & 79 & 82.29 & & \\
\hline Grain & 9 & 7 & 77.77 & & \\
\hline \multicolumn{6}{|l|}{ Housing } \\
\hline Good & 72 & 56 & 77.77 & 4.32 & $0.037 *$ \\
\hline Poor & 103 & 92 & 89.32 & & \\
\hline \multicolumn{6}{|l|}{ Health status } \\
\hline Healthy & 112 & 89 & 79.46 & 6.93 & $0.031 *$ \\
\hline
\end{tabular}

\section{Discussion}

The coprological examination done for the current study using floatation and sedimentation techniques revealed an overall gastrointestinal parasites prevalence to be $84.57 \%$ which is higher than earlier reports of Singh et al. (2012), Goraya et al. (2013), Matto et al. (2015), and Ali et al. (2018) who reported the prevalence rates to be $20.63 \%, 32.2 \%, 72 \%$ and $74.06 \%$ in organized farms of Mumbai and Pune, Upper Punjab of Pakistan, Bajaur and Mohmand agencies of Northwest Pakistan and Jammu region of India respectively. High prevalence reported might be due to variation in sampling time as seasonality affects the occurrence of the parasites, feeding practice and, deworming habit (Regassa and Yimer 2013). In this study, the prevalence of $88.57 \%$ and $81.90 \%$ was recorded in mules and horses respectively the difference being statically non-significant $(\mathrm{p}>0.05)$. This is higher than the study of Sapkota (2009), Matto et al. (2015), and Tahir et al. (2016) who reported the prevalence of $14.80 \%, 43.79 \%$, and $45 \%$ in Mumbai \& Pune of India, Faisalabad region of Pakistan and Lalitpur district of Nepal respectively, but lower than the Karki and Manandhar (2006) who reported the prevalence rate of $100 \%$ in Udayapur district of Nepal. Similarly, the prevalence rate in horses $(81.90 \%)$ observed in the present study almost correlates with the study carried by Adeppa et al. (2016) in the Shimoga region of India and Oli and Subedi (2018) in Rukum District of Nepal who reported the prevalence of $84 \%$ and $84.76 \%$ respectively, but is lower than the findings of Berhanu et al. (2014) and Hasson (2014) who reported an overall prevalence of 97.9\% and 100\% in Hawassa Town Ethiopia and Baquba city Iraq respectively. The present findings is higher than the reports of Yadav et al. (2014), Matto et al. (2015), Tahir et al. (2016), Ali et al. (2018), and Khan et al. (2020) who reported the prevalence rates of $38.69 \%, 38.79 \%$, $43.33 \%, 44.6 \%$ and $59.25 \%$ in Faisalabad region of Pakistan, Organized farms of Mumbai and Pune, Government farm Sargodha of Pakistan, Bajaur and Mohmand agencies of Northwest Pakistan and Jabalpur of North India respectively. The variation in results regarding workers from different regions might be due to variation in the management system, geographical and climatic condition, sample size, sample collection period, and sampling method differences (Oli and Subedi 2018). The higher prevalence of gastrointestinal parasites in both horses and, mules could be due to poor feeding practice, high exposure in pasture grazing, inadequate resting time, excessive work burden and, less attention from the owners of the study area.

The highest prevalence of Strongyles in both species (80\% in mules and $68.57 \%$ in horses) is almost in accordance with the studies of Umar et al. (2013) and Kachhawa et al. (2015) in horses of Nigeria and Bikaner Rajasthan of India who reported prevalence of $68.8 \%$ and $68.18 \%$ respectively. The prevalence of Strongyles in the current study is higher than $10.01 \%, 10.81 \%$, and $14.90 \%$ as reported by Pilania et al. (2012), Matto et al. (2015), and Tahir et al. (2016) in equines of Rajsthan, organized farms of Mumbai \& Pune and Faisalabad region of Pakistan respectively, but is lower than $100 \%$ prevalence reported by Karki and Manandhar (2006) in mules from Udayapur district of Nepal. Similarly, the prevalence of Strongyloides spp. reported to be $23.80 \%$ in horses and $28.57 \%$ in mules is in agreement with the previous reports of $22.72 \%$ and $28.4 \%$ prevalence in equines from Hawasa town Ethiopia and Al Diwaniyah Governorate Iraq as reported by Wannas (2012) and Berhanu et al. (2014) respectively. Prevalence of Strongyloides spp. reported in the present study is higher than earlier reports of Maria et al. (2012), Matto et al. (2015) and Ali et al. (2018) who reported prevalences of $13.19 \%, 6.90 \%$, and $0.14 \%$ in Mumbai and Pune, the central zone of Kashmir valley and Northwest Pakistan respectively.

The prevalence rate of Parascaris equorum in horses was $14.28 \%$ which is closely related to prevalence of $15.51 \%$ reported by Sultan et al. (2014) from Kurfa Chale Ethiopia, but is lower than prevalence $(33.33 \%)$ reported by Khan et al. (2020) from Sargodha Pakistan and higher than $7.09 \%$ and $10.47 \%$ prevalence reported by Pilania et al. (2012) and Oli and Subedi (2018) from horses of Rajasthan India and Rukum district of Nepal respectively. Similarly, the prevalence rate of Parascaris equorum in mules was $35.71 \%$ which correlates with the prevalence of $34.60 \%$ reported from equines by Tahir et al. (2016) in Faisalabad region of Pakistan but lower than prevalence (50\%) reported by Karki and Manandhar (2006) in mules of Udayapur district Nepal. The present findings are higher than the findings of Matto et al. (2015) who reported prevalence of $0.23 \%$ in equines from organized farms of Mumbai \& Pune. The difference in the prevalence of Parascaris equorum from other workers could be due to compromised immune responses related to concurrent diseases (Upjohn et al. 2010). Moreover, the prevalence of $5.71 \%$ of larvae of Dictyocaulus spp. recorded only from mules in the present study almost correlates with the study carried out at brick kiln of Lalitpur Nepal by Sapkota (2009), but is higher than previous studies of Saeed et al. (2010), Tolossa and Ashenafi (2013), and Matto et al. (2015) who reported prevalence of $0.5 \%, 2.5 \%$, and $0.23 \%$ 
respectively. The reports of Umar et al. (2013) and Ali et al. (2018) with prevalence of $10.4 \%$ and $13.62 \%$ is higher than the prevalence of Dictyocaulus spp. reported in the present study. Climatic and environmental differences and differences in access to drugs may partly explain the variation (Mezgebu et al. 2013; Adeppa et al. 2016).

Regarding the risk factor analysis, the current study reported non-significant association between species, study areas, age, and feeding practice and prevalence of equine gastrointestinal parasites while significant statistical difference was observed between the prevalence of equine gastrointestinal parasites and infection status, housing condition and health status. The variations in prevalence rate among four villages could be mainly due to altitudinal and habitat variation (Oli and Subedi 2018). The upland of cooler areas and habitat near river or water origin had more prevalence than lowland (Courtney 1999). Overall 32.57\% of positive samples had mixed infection with the highest prevalence shown by Strongyles and Strongyloides spp. $(12.38 \%)$ in horses and Strongyles and Parascaris equorum (18.57\%) in mules. Mixed infection observed in the current study is higher than the previous findings of Singh et al. (2012), Matto et al. (2015), and Khan et al. (2020) who reported the prevalence of $5.44 \%, 10.26 \%$, and $12.43 \%$ in organized farms of Mumbai and Pune, Sargodha Pakistan, and Jammu region of India respectively. Higher mixed infection in equines could be due to lack of de-worming programs, very less use of antiparasitic drugs, dietary deficiency and poor management system (Saeed et al. 2010; Mezgebu et al. 2013).

The prevalence in young equines was $93.33 \%$ while the prevalence in adult and old equines was $83.05 \%$ and $85.71 \%$ respectively which is higher than the findings of Tesfu et al. (2014) and Taye (2017) of Mekelle and Hawasaa town of Ethiopia respectively. Strongyles eggs predominated in all the infected young equines which could be due to lack of immunity in the younger population (Taye 2017). On contrary to our report, a higher prevalence rate among old equines ( $>10$ years) has been reported by different studies attributing it to deteriorating body condition and senile immune suppression (Sapkota 2009; Ali et al. 2018). Several previous epidemiological investigations have found that young horses are more susceptible to nematode infection than older horses (Saeed et al. 2010; Tesfu et al. 2014). A Higher prevalence $(88.57 \%)$ was observed among equines that graze on pastures. This could be due to the fact that grazing animals are more likely to be exposed to parasites from the grass (Taye 2017). Poor housing condition was another factor that contributed to acquiring gastrointestinal parasites in equines as higher prevalence of $89.32 \%$ was observed which correlates with the previous finding of Mezgebu et al. (2013) at Gondar Town Ethiopia. Based on the health status of equines, the prevalence of gastrointestinal parasites was $100 \%$ in emaciated equines, $91.30 \%$ in weak, and $79.46 \%$ in strong equines which is in line with the study of Ali et al. (2018) who reported $100 \%$ prevalence in emaciated equines at Mohmand and Bajaur Agencies of North-West Pakistan. This might be because of the result of parasitosis on animals (Taye 2017).
In conclusion, the study carried out in four villages of Mustang district revealed higher occurrence of gastrointestinal parasites with an overall prevalence of $84.57 \%$. The prevalence was found to be $81.90 \%$ and $88.57 \%$ in horses and mules respectively. The identified gastrointestinal parasites include eggs of Strongyles, Strongyloides spp., Parascaris equorum and larvae of Dictyocaulus spp. The highest prevalence of Strongyles in both species equines. The prevalence of equine's gastrointestinal parasites showed no significant variation with respect to parameters like host's species, age, study area and feeding status. However, prevalence rate was significantly associated with housing condition, infection status, and health status, which were important risk factors for equine gastrointestinal parasitism in the study area.

\section{ACKNOWLEDGEMENTS}

The authors are very thankful to the owner of the equine of study area for their help and support during sample collection. The authors are grateful to Central Department of Zoology, Tribhuvan University, Nepal for allowing access to their laboratory and necessary materials. Moreover, we are highly grateful to University Grant Commission, Nepal for providing the financial support.

\section{REFERENCES}

Adeppa J, Ananda KJ, Satheesha GM. 2016. Incidence of gastrointestinal parasites in horses of Shimoga region, Karnataka state. J Parasit Dis 40: 919-921. DOI: 10.1007/s12639-014-0605-5.

Ali H, Tauseef I, Haleem SK, Ullah I, Shah AB, Khattak MNK, Mahmood S, Khan MF, Rashid A, Rehman AU. 2018. Prevalence of gastrointestinal nematodes in equines of Bajaur and Mohmand agencies, north-west Pakistan. J Anim Plant Sci 28 (3): 695-701.

Asefa Z, Kumsa B, Endebu B, Gizachew A, Merg T. 2011. Endoparasites of donkey in Sululta and Gefersa districts of central Oromia, Ethiopia. $\begin{array}{llll}\text { J Anim Vet Adv } 10 \quad \text { (14): } 1850-1854 & \text { DOI: }\end{array}$ 10.3923/javaa.2011.1850.1854.

Berhanu T, Ibrahim N, Deressa B, Tolosa T. 2014. Prevalence of helminth parasites of horses in and around Hawassa town, Southern Ethiopia. Acta Parasitol Globalis 5 (1): 7-11.

Brady HA, Nichols WT. 2009. Drug resistance in equine parasites: an emerging global problem. J Equine Vet Sci 29 (5): 285-295. DOI: 10.1016/j.jevs.2009.04.186.

Courtney CH. 1999. Seasonal transmission of equine cyathostomes in warm climates. Vet Parasitol 85 (2-3): 173-180. DOI: 10.1016/S03044017(99)00097-7.

Debere D, Muktar Y, Shiferaw S, Belina D. 2018. Internal parasites of equines and associated risk factors in and around Guder town, West Shewa, central Ethiopia. Ethiop Vet J 22 (2): 36-52. DOI: 10.4314/evj.v22i2.4.

Getachew M, Alemayehu F, Chala C, Amare B, Kassa D, Burden F, Wernery R, Wernery U. 2014. A cross-sectional serosurvey of some infectious diseases of working equids in central Ethiopia. J Vet Med Anim Health 6: 231-238. DOI: 10.4314/evj.v22i2.4.

Goraya K, Iqbal Z, Sajid MS, Muhammad G. 2013. Frequency distribution of equine diseases in three metropolises of upper Punjab, Pakistan. Int J Agric Biol 15: 1067-1074.

Hasson RH. 2014. A study in the prevalence of horses helminths parasitic infection in Baquba city, Diyala province. Int J Recent Sci Res 5 (10): 1810-1813.

Kachhawa JP, Singh AP, Dedar R. 2015. Epidemiological studies on helminthiasis in horses in Bikaner region of Rajasthan. Indian Vet $\mathbf{J}$ 92 (4): 100-101. 
Karki K, Manandhar P. 2006. Preliminary investigation of prevalence of gastrointestinal parasites of mules in Udayapur district. Vet World Res 1:107-109.

Khan RM, Tunio MT, Hussain I. 2020. A study on prevalence of gastrointestinal parasites and their impact on haematological indices in horses stabled at government farm Sargodha, Pakistan. J Agric Res 58 (1): 27-34.

Lashari MH, Tasawar Z. 2011. Prevalence of some gastrointestinal parasites in sheep in southern Punjab, Pakistan. Pak Vet J 31 (4): 295 298.

Maria A, Shahardar RA, Bushra M. 2012. Prevalence of gastrointestina helminth parasites of equines in central zone of Kashmir Valley. Indian J Anim Sci 82 (11): 1276-1280.

Matto TN, Bharkad GP, Bhat SA. 2015. Prevalence of gastrointestinal helminth parasites of equids from organized farms of Mumbai and Pune. J Parasit Dis 39: 179-185. DOI: 10.1007/s12639-013-0315-4.

Mezgebu T, Tafess K, Tamiru F. 2013. Prevalence of gastrointestinal parasites of horses and donkeys in and around Gondar town, Ethiopia. Open J Vet Med 3: 267-272. DOI 10.4236/ojvm.2013.36043.

Oli N, Subedi JR. 2018. Prevalence of gastrointestinal parasites of horse (Equus caballus Linnaeus, 1758) in seven village development committees of Rukum District, Nepal. J Inst Sci Technol 22 (2): 7075. DOI: 10.3126/jist.v22i2.19596.

Pilania PK, Manohar GS, Bhan AK. 2012. Prevalence of gastrointestinal Parasitoses in horses of animal fairs in Rajasthan. Vet Pract 13 (2): 157-159.

Regassa A, Yimer E. 2013. Gastrointestinal parasites of equines in south Wollo zone, north eastern Ethiopia. Glob Vet 11 (6): 824-830. DOI: 10.5829/idosi.gv.2013.11.6.76207

Ivet CR. 2020. Protocol for the management of abandoned equines or kep inadequate welfare conditions. Facultat de Veterinària, Universitat Autònoma de Barcelona, Barcelona.

Saeed K, Qadir Z, Ashraf K, Ahmad N. 2010. Role of intrinsic and extrinsic epidemiological factors on strongylosis in horses. J Anim Plant Sci 20 (4): 277-280.

Sapkota RC. 2009. Prevalence of Helminthes Parasites in Mules in Brick Kiln of Lalitpur District. [Thesis]. Himalayan College of Agricultura Sciences and Technology, Purbanchal University, Gatthaghar, Bhaktapur.
Singh G, Soodan JS, Singla LD, Khajuria JK. 2012. Epidemiological studies on gastrointestinal helminths in horses and mules. Vet Pract 13 (1): 23-27.

Sori G, Bekele T, Geso G, Ibrahim H, Gobena F, Jarso G, Melaku M, Shumet A. 2017. Prevalence of equine strongyle infection and its associated risk factors in Jimma Town, Southwest Ethiopia. Int J Livest Prod 8 (11): 187-191. DOI: 10.5897/IJLP2016.0325.

Soulsby EJL. 1982. Helminths, Arthropods and Protozoa of domesticated animals. $7^{\text {th }}$ ed. Eastbourne, United Kingdom.

Sultan A, Ayele G, Tadesse B, Ahmed A. 2014. Prevalence of gastrointestinal parasites of horses and donkeys in Kurfa Chale District, East Hararghe, Ethiopia. Livest Res Rural 26 (7): 23-27.

Tahir UB, Sajid MS, Khan MN, Saqib M, Siddique RM, Qudoos A. 2016. Passive surveillance and risk analysis of gastrointestinal parasitism in equine population of Faisalabad metropolitan, Pakistan. J Anim Plant Sci 26 (2): 395-400.

Taye A. 2017. Epidemiological study on equine gastrointestinal helminth parasites in Mekelle, North Ethiopia. Open J Vet Med 7 (10): 121130. DOI: $10.4236 /$ ojvm.2017.710012.

Tedla M, Abichu B. 2018. Cross-sectional study on gastrointestinal parasites of equids in South-western Ethiopia. Parasite Epidemiol Control 3 (4): e00076. DOI: 10.1016/j.parepi.2018.e00076.

Tesfu N, Asrade B, Abebe R, Kasaye S. 2014. Prevalence and risk factors of gastrointestinal nematode parasites of horse and donkeys in Hawassa town, Ethiopia. J Vet Sci Technol 5 (5): 2157-7579. DOI: $10.4172 / 2157-7579.1000210$

Tolossa YH, Ashenafi H. 2013. Epidemiological study on gastrointestinal helminths of horses in Arsi-Bale highlands of Oromiya Region, Ethiopia. Ethiop Vet J 17 (2): 51-62. DOI: 10.4314/evj.v17i2.4.

Umar YA, Maikaje DB, Garba UM, Alhassan MA. 2013. Prevalence of gastrointestinal parasites in horses used for cadets training in Nigeria. J Vet Adv 3 (2): 43-48. DOI: 10.5455/jva.20130219032443.

Upjohn MM, Shipton K, Lerotholi T, Attwood G, Verheyen KL. 2010. Coprological prevalence and intensity of helminth infection in working horses in Lesotho. Trop Anim Health Pro 42: 1655-1661. DOI: $10.1007 / \mathrm{s} 11250-010-9617-\mathrm{z}$.

Wannas HY. 2012. Prevalence of gastrointestinal parasites in horses and donkeys in Al Diwaniyah governorate. Al-Qadisiyah J Vet Med Sci 11 (1): 148-155. DOI: 10.29079/vol11 iss1art183.

Yadav KS, Shukla PC, Gupta DK, Mishra A. 2014. Prevalence of gastrointestinal nematodes in horses of Jabalpur region. Res $\mathrm{J}$ Vet Pract 2 (3): 44-48. DOI: 10.14737/journal.rjvp/2014/2.3.44.48. 